\title{
A Noise Impact Assessment Model for Passive Acoustic Measurements of Seabed Gas Fluxes
}

\author{
Jianghui Li ${ }^{\mathrm{a}, *}$, Paul R. White ${ }^{\mathrm{a}}$, Jonathan M. Bull ${ }^{\mathrm{b}}$, Timothy G. Leighton ${ }^{\mathrm{a}}$ \\ ${ }^{a}$ Institute of Sound and Vibration Research, University of Southampton, Southampton, SO17 1BJ, U.K. \\ ${ }^{b}$ Ocean and Earth Science, University of Southampton, National Oceanography Centre, Southampton, SO14 3ZH, U.K.
}

\begin{abstract}
Accurate determination of seabed gas flux is important for understanding natural processes as well as giving confidence that the size of any leaks from marine infrastructure can be properly assessed. Acoustic methods for flux determination require a relatively quiet underwater environment, and can fail when there is too much noise from other natural or anthropogenic sources. This study applies an acoustic monitoring example of seabed gas leakage in terms of sound level intensity, to statistically assess and minimize the impact from oceanic noise on seabed acoustic experiments which require relative quiet environment. It addresses the question: how far from a source of radiated ambient noise does a recording hydrophone and location of seabed gas need to be so that acoustic methods for remotely determining gas flux are successful. We develop a model to assess impacts of ambient noise under various conditions, incorporating sound/noise sources (seabed gas leaks, sea surface agitation and shipping) and underwater acoustic propagation. The reliability of the model is tested by comparing measured seabed ambient noise in the central North Sea, and the robustness of it is verified by presenting statistical outliers and a receiver operating characteristic (ROC) curve. A range of scenarios are presented for several gas flow rates, which show the threshold of detection when the recording hydrophone is at different distances from the location of seabed gas escape, and competing noise sources (including shipping and surface waves).
\end{abstract}

Keywords: acoustics, ambient noise, seabed gas flux, carbon dioxide, Carbon Capture and Storage.

\section{Introduction}

In the past decades, the increasing level of greenhouse gas, including carbon dioxide $\left(\mathrm{CO}_{2}\right)$ [1], has resulted in global climate change manifest by the melting of sea ice [2, the rise of sea level, and the disappearance of wetlands 3 . For mitigating climate change caused by anthropogenic emissions of green-house gases, sub-seabed storage of $\mathrm{CO}_{2}$ in Carbon Capture and Storage (CCS) facilities has been discussed as one of a range of technologies that could be used [4, 5, 6, 7]. A key issue with CCS is ensuring that sequestered gas remains in the sub-surface, and that any significant leakage is detectable. In the marine environment there has been experimentation to determine the limits for this detection, as well as localization and quantification of $\mathrm{CO}_{2}$ leakage from controlled subseabed gas release experiments [8, 9, 10, 11, 12, 13. With regard to quantifying gas leakage using acoustic techniques, ambient noise is an essential factor that needs to be considered [14. Acoustic

*Corresponding author: Jianghui Li techniques are critically dependent on discrimination of bubble sounds from background noise to allow measurement of bubble radii and flux rates [15].

In the ocean, ambient noise can be radiated from turbulence, surface wave agitation, thermal agitation, seismic events, rainfall, marine animals, ice sheet cracking, and shipping [16, 17, 18, 19, 20, 21, 22, 23]. The bubble source spectrum of interest for bubbles released from the seabed (where bubbles tend to be larger than those generated by breaking ocean waves) [24, 25 is usually within a frequency band from hundreds of $\mathrm{Hz}$ up to around $25 \mathrm{kHz}$ for small/moderate-sized injection points [15, 26]. The frequency band is particularly affected by ambient noise produced from the sea surface [19. 20, as well as ship noise [27, 28, 21, 22, 23. Noise outside this frequency band is usually not of concern 29]. The interaction of the two types of noise sources and how they may affect the acoustic measurements, provides the impetus for this investigation. The approach taken here is to build a model to assess the impacts of ambient noise, by considering acoustic signals produced by oscillating bubbles as well as the noise received by the acoustic 
receiver.

Considering a prediction of acoustic carbon dioxide emission during a leak, Leighton and White [15] described a method which provides quantitative measurements of gas leakage, which is applicable to a range of scenarios including from CCS facilities and natural methane seeps. In this initial study, the acoustic spreading loss is considered as spherical and the propagation losses are not considered, which is a simplification and unrealistic for remote acoustic detection. In an underwater environment, the effect of the seabed can be a potential problem, and is controlled by the sound speed profile (SSP) and physical characteristics of the sediment in the channel. The SSP and seabed parameters usually vary significantly at different field sites, which makes the sound propagation complicated and can be critical impact factor in underwater acoustics [30, 31, 32. For detecting bubble sounds, an acoustic receiver, e.g., a single omnidirectional hydrophone or an array of hydrophones, is usually employed. The position of the receiver relative to the centre of the gas seep is a critical factor when determining the performance of a system.

Sea surface generated noise is probably the most pervasive contributor to underwater noise in the ocean, particularly in areas affected by strong winds or in shallow water. Normally, the magnitude of the agitation noise is controlled by the strength of the wind blowing over the surface, causing breaking waves 27. and entraining bubbles 33. The breaking waves then immediately radiate sound 34 , 35, such that the level of surface noise depends on the strength of the wind [28]. In underwater environments, ship noise is another significant contributor, which can cause substantial elevation of ambient noise [17, and affect the ability to detect and quantify leaks. The ship noise, including transit noise and traffic noise 36, can be a dominant noise source, especially the transit noise, i.e., noise from a vessel travels in the vicinity of acoustic receiver, where there is little propagation loss in the acoustic channel [29]. To assess the impact of nearby shipping, we compute the distance at which a vessel is likely to hinder detection of a leak.

To determine whether detection of a leak is likely to occur, the signal-to-noise ratio (SNR) is calculated and compared to the Detection Threshold (DT). The value of DT incorporates the probability of detection (PD) and the probability of false alarm (PFA) 37, 38. For example, for a $\mathrm{PD}$ of $50 \%$ and a PFA of $0.01 \%$ in Gaussian noise background, the DT is $6 \mathrm{~dB} 38$. The gas flow rate and the acoustic source level of the injected bubble are critical factors when determining the SNR.
Leighton and White [15] highlighted the lack of information on the source level, and that reliance on the literature and simple calculations to infer a source level was unsatisfactory and could lead to inaccuracies. The gas flow rate varies in different marine/laboratory experiments and natural seeps, and determines the intensity of the sound radiated by the bubbles [39, 40]. For example, the QICS (Quantifying and Monitoring Potential Ecosystem Impacts of Geological Carbon Storage) $\mathrm{CO}_{2}$ release experiment [8, 12, 11] was carried out in Ardmuchnish Bay (10-12 m depth) with gas leakage rate estimated between approximately 0.1 and $18 \mathrm{~L} / \mathrm{min}$ [8]. Laboratory experiments, such as 41, estimated leakage rates between 2 and 12 L/min. Further, numerous natural gas seeps have been discovered worldwide [42, 43, 41, 44, 45, 46, 47, and some of them were quantified from single seep vents: the reported leaks rates range from $0.1 \mathrm{~L} / \mathrm{min}$ to $78 \mathrm{~L} / \mathrm{min}$.

In this paper, to assess the underwater ambient noise, particularly the ship noise, in light of the potential impacts to gas flux measurements, we develop a passive acoustic model. The bubble acoustic signal is predicted from the gas flow rate and the distribution of bubble sizes at the point of formation. The underwater sound propagation is simulated using the Bellhop ray-tracing program [48, to predict acoustic pressure field in ocean environments. In the modelling, we consider various conditions, involving underwater gas flow rates $(0.5-18 \mathrm{~L} / \mathrm{min})$, wind speeds over the sea surface, ship noise source levels, ranges between acoustic receiver and gas seep centre $(0.5-12 \mathrm{~m})$, (nearby) ship distances to the receiver (0-5 km), and (distant) shipping density and distribution. A detection threshold of the receiver is applied to predict maximum hydrophone/bubble ranges and minimum ship/hydrophone distances. We take the central North Sea as an example of the modelled environment at a depth of $150 \mathrm{~m}$.

This paper is organized as follows. Section 2 introduces the measurement scenario and model framework, while Section 3 describes the bubble sound simulator. Section 4 describes the ambient noise modelling, including noise radiated from sea surface agitation and shipping, and propagation loss in the acoustic propagation channel. Section 5 processes acoustic signals in the receiver. Section 6 displays simulation results, and Section 7 justifies the model with experimental data and statistical analysis. Section 8 completes the paper with concluding remarks, discussions, and gives outlooks for future work. 


\section{Measurement scenario and model frame- work}

In underwater acoustic environments, a sound source having a Source Level (SL) subjected to propagation loss (PL), will have the following Spectral Receive Level (SRL) at the hydrophone:

$$
\mathrm{SRL}=\mathrm{SL}-\mathrm{PL} \text {. }
$$

The Source Level (SL) represents the sound radiated underwater by the source and is always referred to a standard range (1 $\mathrm{m}$ adopted here) from the acoustic centre of the source. The Source Level (SL) is expressed as a power density and measured in $\mathrm{dB}$ re $1 \mu \mathrm{Pa}^{2} / \mathrm{Hz}$ at $1 \mathrm{~m}$. The PL $[\mathrm{dB}]$ represents the power loss due to the propagation of the signal through the water column between the sound source and the hydrophone. Essentially, it is a function of two terms: the geometrical loss $\mathrm{PL}_{g}$ and the absorption loss $\mathrm{PL}_{\alpha}$ :

$$
\mathrm{PL}=\mathrm{PL}_{g}+\mathrm{PL}_{\alpha} \text {. }
$$

The geometrical loss $\mathrm{PL}_{g}$ considers the geometrical spreading of sound wave, and the $\mathrm{PL}_{\alpha}$ is the effect of absorption, both in the water column and seabed. In seeking to detect a gas leakage, we are concerned with both the sound made by the bubbles and the ambient noise (sea surface noise and ship noise), as shown in Figure 11. The potential for the noise to mask the bubble sounds can be estimated based on the signal-to-noise ratio (SNR) 49]:

$$
\mathrm{SNR}=\mathrm{SPL}_{\mathrm{b}}-\mathrm{NPL}
$$

where $\mathrm{SNR}$ is measured on a receive hydrophone expressed in $\mathrm{dB}, \mathrm{SRL}_{\mathrm{b}}$ is the SRL of the bubble signature, and NPL is the noise pressure level.

Figure 2 shows the block diagram of the noise impact assessment simulator. In the simulator, there are blocks representing the bubble sound, ship transit and traffic noise and sea surface noise generators, propagation models, and hydrophone signal processing model.

\section{Bubble Sound Simulator}

As a bubble is released into the water column, it undergoes fluctuations in its volume which efficiently radiates sound [50]. The bubble acoustic signal, which is the sound of interest, is used for gas quantification at the receive hydrophone. At the hydrophone, the SRL of bubbles $\left(\mathrm{SRL}_{\mathrm{b}}\right)$ can be expressed as:

$$
\mathrm{SRL}_{\mathrm{b}}=\mathrm{SL}_{\mathrm{b}}-\mathrm{PL}_{\mathrm{b}}
$$

where $\mathrm{SL}_{\mathrm{b}}$ is the bubble sound source level, depending on the bubble signal intensity in the frequency range of interest, and $\mathrm{PL}_{\mathrm{b}}$ is the propagation loss associated with the bubble sound. The sound propagation in underwater acoustic environments are complicated and vary among different field sites in the ocean, then the propagation cannot be simply described as spherical or cylindrical propagation. Herein, the Bellhop program 48] is applied as the propagation model to calculate sound propagation loss in the channel. In the Bellhop calculation, we consider the rays combined coherently in a medium in the sense that the pressure signatures are summed [18.

\subsection{Bubble Sound Generator}

To model the bubble sound generator, two steps are considered: the creation of probability density function (PDF) of bubble equilibrium radius, and the computation of approximate acoustic emission detected in the far field. This probability density function PDF is a statistical representation of the number of bubbles emitted per second as a function of radius.

\subsubsection{Creating PDF of bubble equilibrium radius}

We consider the probability density function (PDF) of the bubble radius as being approximated by a lognormal distribution [51, 52, [53, [54]:

$$
p_{\mathrm{b}}^{R}=\frac{1}{R \sigma_{l} \sqrt{2 \pi}} e^{\left(-\left(\ln R-\mu_{l}\right)^{2} / 2 \sigma_{l}^{2}\right)},
$$

where $\sigma_{l}$ is the lognormal mean value $[\mathrm{m}], \mu_{l}$ is the lognormal standard deviation $[\mathrm{m}]$, and $R$ is the bubble radius $[\mathrm{m}]$. With the bubble radius distribution $p_{\mathrm{b}}$, the mean volume across the bubble population $V_{m}$ [55] can be computed. Then, the average number of bubbles per second is given by:

$$
N_{\mathrm{b}}=V_{r} / V_{m},
$$

where $V_{r}$ is the gas flow rate $\left[\mathrm{m}^{3} / \mathrm{s}\right]$. Note that the flow rate composes of components from both large bubbles and small bubbles. Through a large opening, the size of leaked bubble is larger than that from a small opening. The low pressure of large bubbles makes low ratio of $R_{\varepsilon 0 i} / R_{0}$ (see Eq. 7) corresponding to relative low frequency noise, while the high pressure of small bubbles makes high ratio of $R_{\varepsilon 0 i} / R_{0}$ corresponding to relative high frequency noise.

\subsubsection{Far field acoustic emission of the bubbles}

Leighton and White [15] identified the lack of a validated model for the source strength of a bubble emitted from a seabed as the major limitation in implementing their approach. Until an improved model becomes available, we will use their interim model to demonstrate the method. For a single bubble emitted from a leak, assume the bubble oscillates in a limit of small amplitude $\left|R_{\varepsilon}\right| \ll R_{0}$, 


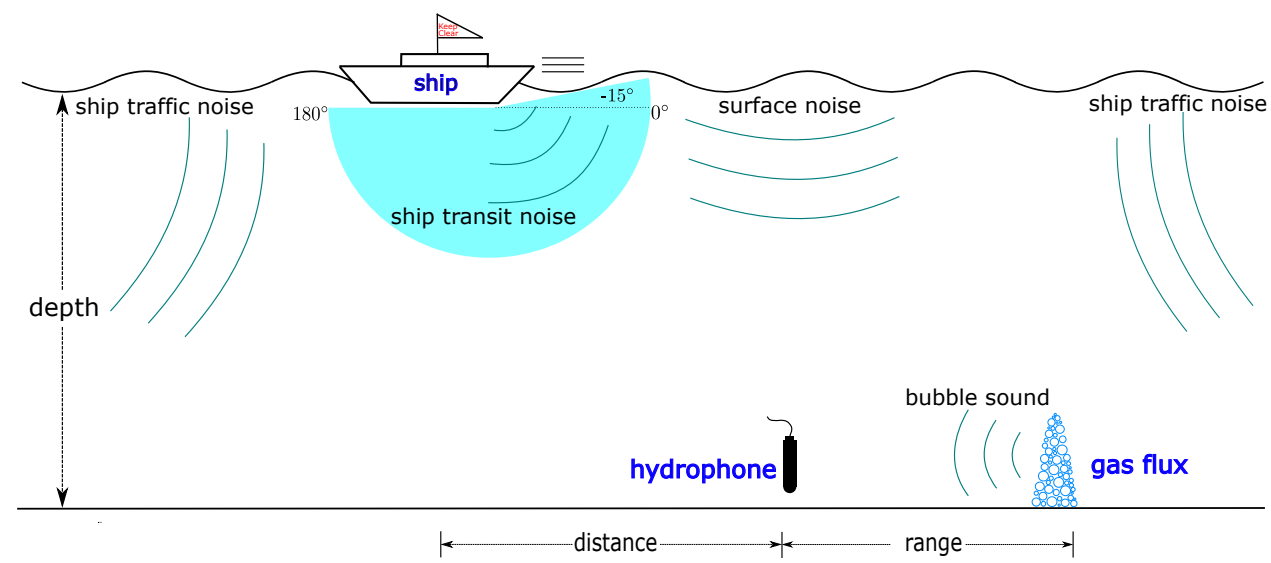

Figure 1: Modelled gas flux measurement scenario. Noise is contributed from the sea surface and shipping. The model investigates the relative contributions of bubble emissions and ambient noise at different ranges/distances of the recording hydrophone from the sound sources.

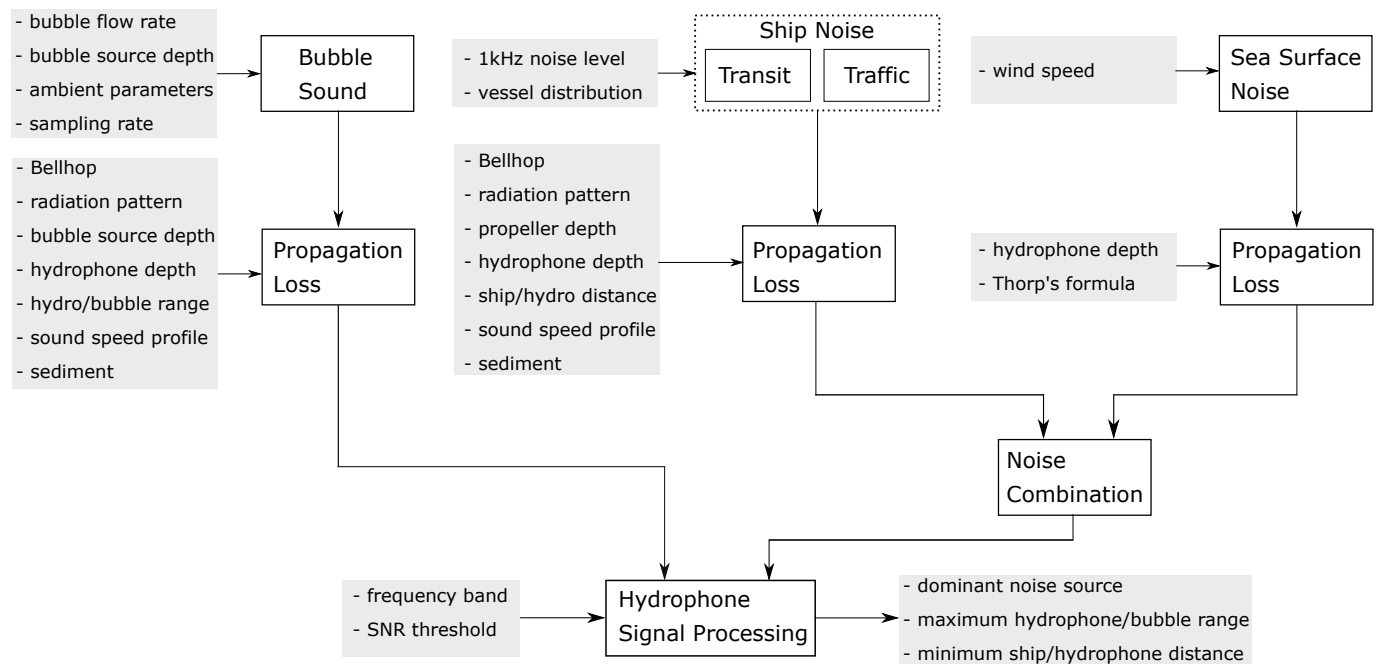

Figure 2: Flowchart of the passive acoustic model, shows the dependencies in the integrated underwater noise impact assessment modelling approach.

which is valid for most ocean gas bubbles pulsating at their natural frequencies [56]. The oscillatory pressure signature in the liquid $P_{\mathrm{b} 1}(t)$ of the monopole emission detected at time $t$ by a hydrophone in the far field for a single pulsating bubble, is given by [15]:

$$
\begin{aligned}
P_{\mathrm{b} 1}^{R_{0}}\left(t, t_{i}\right)= & \left(\omega_{0} R_{0}\right)^{2} \frac{\rho_{0}}{r_{1}} R_{\varepsilon 0 i} e^{-\omega_{0} \delta_{t o t}\left(t-t_{i}\right) / 2} \\
& \times H\left(t-t_{i}\right) \cos \omega_{0}\left(t-t_{i}\right),
\end{aligned}
$$

where $R_{0}$ is the bubble equilibrium radius [m], $\rho_{0}$ is the ambient liquid density $\left[\mathrm{kg} / \mathrm{m}^{3}\right], R_{\varepsilon 0 i}$ is the initial bubble wall amplitude $[\mathrm{m}], \delta_{\text {tot }}$ is the total dimensionless damping coefficient at bubble natural frequency [50, $t_{i}$ is the time at which the acoustic signal is first detected at the monitor, $H$ is the Heaviside step function, and $r_{1}$ is the reference range ( $1 \mathrm{~m}$ adopted here) from the bubble acoustic centre. Low-amplitude pulsations occur at a natural angular frequency $\omega_{0}$, which is given by [50]:

$$
\omega_{0}=\frac{1}{R_{0} \sqrt{\rho_{0}}} \sqrt{3 \kappa\left(p_{0}-p_{\mathrm{v}}+\frac{2 \sigma}{R_{0}}\right)-\frac{2 \sigma}{R_{0}}+p_{\mathrm{v}}-\frac{4 \eta^{2}}{\rho_{0} R_{0}^{2}}},
$$

where $p_{0}$ is the ambient pressure $[\mathrm{Pa}], p_{\mathrm{v}}$ is the vapor pressure $[\mathrm{Pa}], \sigma$ is the surface tension $[\mathrm{N} / \mathrm{m}]$, $\eta$ is the shear viscosity [Pa.s], and $\kappa$ is the ratio of specific heat of the gas at constant pressure to that at constant volume, depending on whether the gas is behaving adiabatically, isothermally, or in some intermediate manner 57.

If the acoustic emissions of the bubbles are all uncorrelated, then the far-field acoustic signature of the bubble cloud (gas flux) can be expressed as

$$
P_{b 1}(t)=\sum_{i=1}^{N_{\mathrm{b}}} P_{b 1}^{R_{0}}\left(t, t_{i}\right), t_{i} \in\left[0 T_{\mathrm{b}}\right],
$$

where $t_{i}$ is randomly distributed in the interval $\left[\begin{array}{ll}0 & T_{\mathrm{b}}\end{array}\right]$, following the bubble radius probability den- 
sity function $\mathrm{PDF} p_{b}^{R_{0}}$.

\subsection{Bubble Sound Propagation Loss}

A bubble can be regarded as omnidirectional source [15, i.e., the power of it is equally radiated in all the directions. However, a lab experiment 58, has shown that for a vertical chain of rising bubbles the distribution of acoustic pressure around a bubble chain revealed a strong anisotropy in the acoustic field, and the sound appeared to propagate much more efficiently along the chain than normal to it. The Bellhop program that we are applying considers this anisotropy by defining the source beam pattern with angle-level pairs 48 . In the calculation of $\mathrm{PL}_{\mathrm{b}}$, the hydrophone is situated at a range of $r$ from the centre of the gas seep. The geometrical loss $\mathrm{PL}_{g}$ modelled as a spherical spreading from the centre of the gas seep to a reference range $r_{1}$, while the sound spreading from the reference range $r_{1}(1 \mathrm{~m})$ to a sensor position $r \geq r_{1}$ are modelled using the Bellhop program with a SSP specific to the field site. The sound attenuation can be from spreading in the water column, scattering from the sea surface and seabed, and the absorption. The absorption loss $\mathrm{PL}_{\alpha}$ in the water column, is related to the temperature, salinity, $\mathrm{pH}$, frequency, the range of the hydrophone to receive acoustic signals, and the depth of the gas release field site. A variety of empirical relationships allowing the prediction of absorption have been proposed, e.g., in [49] and 59], here we adopt that proposed by 60]:

$$
\alpha(f)=\frac{0.1 f^{2}}{1+f^{2}}+\frac{40 f^{2}}{4100+f^{2}}+2.75 \times 10^{-4} f^{2}+0.003,
$$

where $f$ is the frequency $[\mathrm{kHz}]$. At the hydrophone position $r$, the received sound signals are from multipath, and the attenuation coefficient $\alpha(f)$ is applied to all the received multipath signals.

The propagation model estimates the propagation loss as a function of frequency $\mathrm{PL}_{\mathrm{b}}(\omega)$ between the range of $r_{1}=1 \mathrm{~m}$ (the reference position for the source spectral level) and the hydrophone range $r$ :

$$
\mathrm{PL}_{\mathrm{b}}(\omega)=\mathrm{PL}_{\mathrm{b}(r)}(\omega)-\mathrm{PL}_{\mathrm{b}\left(r_{1}\right)}(\omega),
$$

This is computed $\omega_{\text {end }} / \Delta \omega$ times for each $\omega$ value in the frequency band of interest $\left[0 \omega_{\text {end }}\right]$ with a frequency step $\Delta \omega$. Then, the calculated spectral shape $\mathrm{PL}_{\mathrm{b}}(\omega)$ is used to design a finite impulse response (FIR) filter within the frequency band [0 $\left.\omega_{\text {end }}\right]$, and this filter is applied on the bubble sound pressure signal $P_{b 1}(t)$. Allowing the time-domain bubble sound signal $P_{\mathrm{b}(r)}(t)$ at the hydrophone position $r \geq r_{1}$ to be obtained.

\section{Ambient Noise Simulator}

The NPL in Eq.(3), is obtained by summing the contributions of the ambient noise, depending on the receiver bandwidth $B$ and the overall noise spectral level (NSL) at the receiver. The noise spectral level (NSL) $\left[\mathrm{dB}\right.$ re $\left.1 \mu \mathrm{Pa}^{2} / \mathrm{Hz}\right]$ is the power sum of the sound spectrum levels attributable to the predominant noise sources, and can be computed as:

$$
\mathrm{NSL}=10 \log _{10}\left(\sum_{q=1}^{Q} 10^{N S L_{q} / 10}\right),
$$

where $Q$ is the number of noise sources considered within the bandwidth that contains major power of the bubble sound. In this paper, we consider three noise sources $(Q=3)$ : the sea surface agitation noise $(q=1)$, the noise radiated from a single nearby vessel, i.e., ship transit noise $(q=2)$, and the noise radiated from vessels that are too far away to be heard individually 61, i.e., ship traffic noise $(q=3)$. Other noise sources, like turbulence noise (which dominates in the band 1-10 Hz) and thermal noise (dominant over $100 \mathrm{kHz}$ ) [28, are secondary in the major bubble frequency band (usually between hundreds of $\mathrm{Hz}$ and couples of $\mathrm{kHz}$ ). Each noise spectral level $\mathrm{NSL}_{q}$ is expressed as:

$$
\mathrm{NSL}_{q}=\mathrm{SL}_{q}-\mathrm{PL}_{q}, q=1, \ldots, Q,
$$

where $\mathrm{SL}_{q}\left[\mathrm{~dB}\right.$ re $\left.1 \mu \mathrm{Pa}^{2} / \mathrm{Hz}\right]$ is the source level radiated by the $q$ th noise source and the $\mathrm{PL}_{q}[\mathrm{~dB}]$ is its corresponding propagation loss.

To obtain a time-domain sequence with the desired noise spectral level $\mathrm{NSL}_{q}$, the following steps are taken. Firstly, a white Gaussian noise (WGN) signal

$\mathbf{x}=[x(1), \ldots, x(n), \ldots, x(N)]$ is generated with $N$ samples. Then, assign the spectral shape noise spectral level $\mathrm{NSL}_{p}$ on it by designing an FIR filter. Once the three noise sources, i.e., sea surface noise, ship transit noise and ship traffic noise, are generated, they are propagated into the underwater channel, which is simulated using the Bellhop program 48.

\subsection{Sea surface noise}

\subsubsection{Surface noise source}

The magnitude of the sea surface spectral level $\mathrm{SL}_{1}$ depends on the surface conditions and is governed by the wind speed. Empirical relationships between noise spectral level (NSL) and wind speed $v_{\mathrm{w}}[\mathrm{m} / \mathrm{s}]$ exist, one of which, valid in the $100 \mathrm{~Hz}-$ $100 \mathrm{kHz}$ range, is described by [28]:

$$
\mathrm{SL}_{1}(f)=50+7.5 \sqrt{v_{\mathrm{w}}}+20 \log _{10}(f)-40 \log _{10}(f+0.4),(14)
$$$$
\text { where } f \text { is the frequency }[\mathrm{kHz}] \text {. }
$$ 


\subsubsection{Surface noise propagation loss}

For the physical nature of the surface agitation, it is characterized by a distributed noise field. Neglecting reflections from the seabed, surface agitation generates a noise field which has a constant intensity at a given depth, $d$. However, the surface generated noise is affected by absorption as a function of depth $62,63,64$, and can be approximated by:

$$
\mathrm{PL}_{1}(f)=\alpha(f) \times d \mathrm{~dB},
$$

where $\alpha(f)$ is the attenuation coefficient given by Eq. 10 .

\subsection{Ship transit noise}

\subsubsection{Transit noise source}

Underwater noise radiated from a vessel passing nearby is also considered as an acoustic pollutant affecting passive acoustic measurement 65 . The ship transit noise can be considered as being generated by a single nearby vessel with a number of different source mechanisms, e.g., water flow noise, auxiliary machinery and equipment noise, diesel generators noise, electric motors noise, and propeller noise.

For a vessel radiating underwater noise, an empirical equation, which considers the displacement, speed relative to cavitation inception speed, block coefficient as an indicator for wake field variations, mass of diesel engines and diesel engine resiliently mounted, can be taken to model the corresponding $\mathrm{SL}_{2}$ 66:

$$
\mathrm{SL}_{2}(f)=10 \log _{10}\left(\mathrm{~F}_{1}+\mathrm{F}_{2}+\mathrm{F}_{3}\right),
$$

where $\mathrm{F}_{1}$ represents the low-frequency contribution, the $\mathrm{F}_{2}$ represents the high-frequency propeller noise, and the $\mathrm{F}_{3}$ represents the engine noise. The three terms are given by

$$
\begin{aligned}
\mathrm{F}_{1}= & 2.2 \times 10^{-10} f^{5}-2 \times 10^{-7} f^{4}+6 \times 10^{-5} f^{3} \\
& -8 \times 10^{-3} f^{2}+0.35 f+125+\mathrm{A}+\mathrm{B} \\
\mathrm{F}_{2}= & -5 \times \log (f)-1000 / f+10+\mathrm{B}+\mathrm{C} \\
\mathrm{F}_{3}= & 10^{-7} f^{2}-0.03 f+145+\mathrm{D}+\mathrm{E},
\end{aligned}
$$

where

$$
\begin{aligned}
& \mathrm{A}=80 \log _{10}\left(\left(v / v_{\mathrm{CIS}}\right) \times 4 c_{B}\right), \text { speed \& block } \\
& \mathrm{B}=10 \log _{10}\left(\Delta / \Delta_{\mathrm{ref}}\right)^{2 / 3}, \text { displacement, } \\
& \mathrm{C}=60 \log _{10}\left(\left(v / v_{\mathrm{CIS}}\right) \times 1000 c_{B}\right), \text { speed \& block, } \\
& \mathrm{D}=15 \log _{10}(m)+10 \log _{10}(n), \text { engine mass \& number }
\end{aligned}
$$

$$
\mathrm{E}=\left\{\begin{array}{l}
0, \text { engine resiliently mounted }, \\
15, \text { engine rigidly mounted }
\end{array}\right.
$$

In the Eqs. 17) and (18), $f[\mathrm{~Hz}]$ is the frequency of interest, $v[\mathrm{knots}]$ is the speed through water, $v_{\text {CIS }}\left[\right.$ knots] is the cavitation inception speed, $c_{B}$ is the block coefficient, $\Delta[\mathrm{t}]$ is the displacement, $\Delta_{\text {ref }}=10,000 \mathrm{t}$ is the reference displacement, $m[\mathrm{t}]$ is the engine mass, and $n$ is the number of engines operating at the same time. As Wittekind 17 pointed out that the model is still continuously compared to most recent data and has been found reasonable and appropriate, we have adjusted the parameters in Eq.117c to fit the measured data, which will be discussed in Section 7.1.

\subsubsection{Transit noise propagation loss}

An assumption made is that the ship path takes the vessel directly over the top of the field site, so that the ship is always in the same vertical plane as the hydrophone. To predict the received level from a vessel at a distant point, it is important to take into account the directivity of ship noise. The noise radiated from a vessel is usually loudest approximately in angle range $\theta_{\text {ship }} \in$

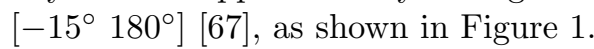

The noise from a vessel is a local non-stationary noise source in the sense that the vessel radiates as a point-like dipole source, which changes its position dynamically, so that the relative distance between the vessel and the hydrophone changes as a function of time. For each position of the vessel, the propagation loss $\left(\mathrm{PL}_{2}\right)$ is computed using Bellhop, considering the effect of the seabed absorption and the multipath structure in the propagation channel.

\subsection{Ship traffic noise}

While one vessel is close to the hydrophone, other vessels are assumed distributed in the surrounding well-defined ocean area on the sea surface [36]. The ship traffic noise $\left(\mathrm{SL}_{3}\right)$ accounts for the cumulative radiating effect of a number of vessels and corresponds to the distribution of these vessels. The ship traffic noise consists of a linear combination of radiated acoustic components from all these distributed vessels recorded by a hydrophone. For each acoustic component, the radiated source level is described by Eq. 16. The attenuation of the radiated noise $\left(\mathrm{PL}_{3}\right)$ from these vessels differs from the relatively large distances to the hydrophone. A more complete model would consider or estimate the statistics and geometries of surrounding vessels. For real-time marine traffic across the oceans, readers are referred to 68 .

\section{Hydrophone Signal Processing}

After the channel propagation of the four sound sources, the SNR at the hydrophone can be computed to estimate the potential for the noise to mask bubble sounds from gas release measurements. To decide whether a detection is made or not at the hydrophone, a SNR detection threshold $[\mathrm{dB}]$ is calculated. The process to determine a detection threshold depends on the PD and the PFA [38. 
The relation between the SNR at the hydrophone output of the signal in Gaussian noise to the detection index is given by [37]:

$$
\mathrm{DT}=5 \log (\dot{d} / B T)
$$

where $B$ is the bandwidth, $T$ is the integration time, and $\dot{d}$ is the detection index, which indicates how easy it is to observe a signal in noise. Urick 49 presented receiver operating characteristic (ROC) curves for both the signal plus and noise as Gaussian probability density function PDF, from which we can find that for a PD of $50 \%$ and a PFA of $0.01 \%$, the detection index is $\dot{d}=16$, and the detection threshold $=6 \mathrm{~dB}$. The value $6 \mathrm{~dB}$ is also imposed in 15 as a detection threshold to determine maximum detection range.

\section{Simulation results}

As an example of the designed model for noise impact assessment, a set of scenarios of passive acoustic measurement of gas fluxes in the central North Sea are considered. Specifically, data from vicinity of the Goldeneye Complex (around $58^{\circ} 38^{\prime} \mathrm{N}$, $01^{\circ} 08^{\prime} \mathrm{E}$ ) is used (Figure 3), which has been considered to be a possible site for CCS [69], and the depth of the seafloor is around $150 \mathrm{~m} \mathrm{[70]}$. The shape of the sea surface is considered as sinusoidal waves, of which the height and period is affected by the wind speed. The seabed is considered as an acousto-elastic half space without layers, because of the high acoustic attenuation at the frequencies emitted by these bubbles $(5-15 \mathrm{kHz}$, say) in the seabed surface layer 71 . In this part of the North Sea, the surface sediment is mostly mud [72, 73], behind which is sand layer, and so an attenuation coefficient of $0.7 \mathrm{~dB} /$ wavelength is appropriate 74 .

In this scenario, the bubbles are generated at the seabed at $150 \mathrm{~m}$ water depth, and the sound radiates omnidirectionally. The sea surface noise is generated by the sea surface agitation, which radiates sound towards the seabed. The ship transit noise source is assumed to be generated at a depth of $2.5 \mathrm{~m}$ with a radiation angle interval from $-15^{\circ}$ (stern) to $180^{\circ}$ (bow) (see Figure 1), so as each component of the ship traffic noise. In the simulation, the SSP shown in Figure 3 is applied. The simulated signals are constructed assuming an omnidirectional hydrophone, which is located close to the seafloor at depth $d=149 \mathrm{~m}$. We simulate a variety of hydrophone ranges relative to the seep's centre, specifically a range $r(0.5-12 \mathrm{~m})$, and the focal vessel is modeled at horizontal distances $D(0-5 \mathrm{~km})$ from the position of the receive hydrophone. The parameters used in the simulations are shown in Table 1. During the simulation, no

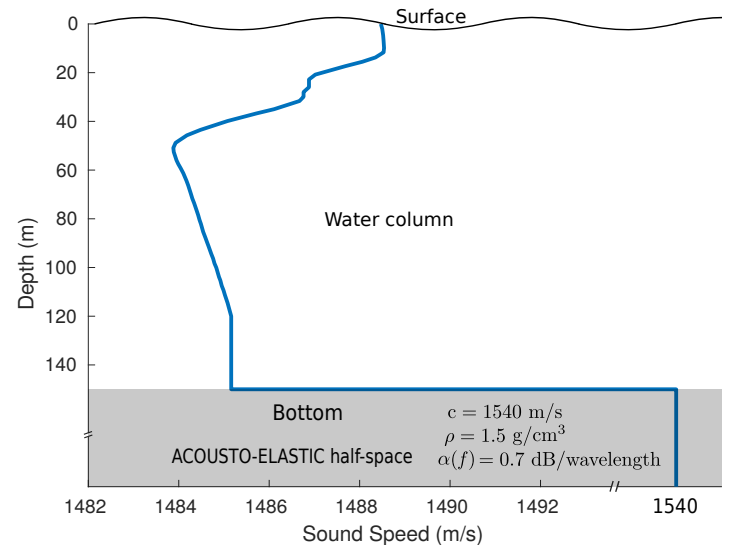

Figure 3: Typical sound speed profile (SSP) at the Goldeneye Complex area of the North Sea at a water depth of $150 \mathrm{~m}$. Seabed parameters (sound speed (c), density $(\rho)$ and wavelength-dependent attenuation coefficient $(\alpha(f)))$ in modelling are indicated.

change in noise contribution from the sea surface and the vessel is assumed. Because of the randomness of the bubble radius generation and the ambient noise generation, 1000 times Monte Carlo simulation with the model has been conducted and the results averaged.

Table 1: Parameters used in the simulations

\begin{tabular}{ccr}
\hline \hline Parameter & symbol & \multicolumn{1}{c}{ value } \\
\hline seafloor depth & & $150 \mathrm{~m}$ \\
bubble source depth & & $150 \mathrm{~m}$ \\
gas flow rate & & $0.5-18 \mathrm{~L} / \mathrm{min}$ \\
seafloor temperature & & $10^{\circ} \mathrm{C}$ \\
highest frequency of interest & $\omega_{\text {end }}$ & $24 \mathrm{kHz}$ \\
frequency step & $\Delta \omega$ & $24 \mathrm{kHz} / 1024$ \\
sea surface wind speed & $v_{\mathrm{w}}$ & $1 \mathrm{knot}$ \\
ship noise source depth & & $2.5 \mathrm{~m}$ \\
ship noise radiation angle & $\theta_{\text {ship }}$ & $-15^{\circ}-180^{\circ}$ \\
receiver(hydrophone) depth & $d$ & $149 \mathrm{~m}$ \\
receiver/bubble range & $r$ & $0.5-12 \mathrm{~m}$ \\
transit ship/receiver distance & $D$ & $0-5 \mathrm{~km}$ \\
traffic ship/receiver distance & $\widehat{D}$ & $5-100 \mathrm{~km}$ \\
SNR detection threshold & $\mathrm{DT}$ & $6 \mathrm{~dB}$ \\
duration of signal time series & $\mathrm{T}$ & $1 \mathrm{~s}$ \\
sampling frequency & $\mathrm{Fs}$ & $48 \mathrm{kHz}$ \\
\hline
\end{tabular}

\subsection{Bubble signals}

We model possible gas leakage through the seabed, by bubble generation at the seafloor $(150 \mathrm{~m})$, with the bubble source spectral level $\left[\mathrm{dB}\right.$ re $\left.1 \mu \mathrm{Pa}^{2} / \mathrm{Hz}\right]$ predicted at $1 \mathrm{~m}$ above the seabed. The default bubble flow rate is set to $4 \mathrm{~L} / \mathrm{min}$, which is a medium sized release experiment [8, 41]. Note that the gas flux is measured as volume at depth, not at standard atmosphere. The parameters $\left(\rho_{0}, p_{0}\right.$, $p_{\mathrm{v}}, \sigma, \eta$, and $\kappa$ ) in Eq. (7) and Eq. (8) are based on those found in [57. Figure 4 shows the probability density function PDF of the bubble radius 
from the lognormal distribution Eq.(5) (number of bubbles generated per second per micron increment in radius range), from which we can see that the bubble radius mainly falls between $0.3 \mathrm{~mm}$ and $2.4 \mathrm{~mm}$.

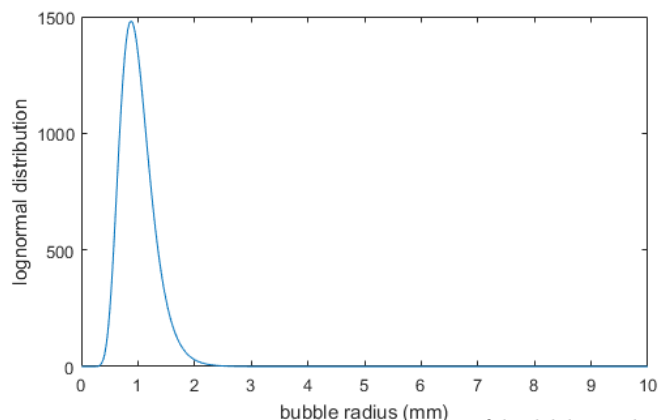

Figure 4: Lognormal distribution of bubble radius.

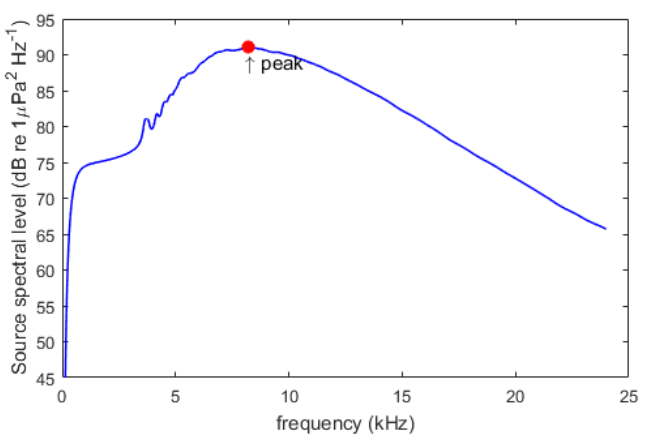

Figure 5: Prediction of the source spectral level $[\mathrm{dB}$ re $\left.1 \mu \mathrm{Pa}^{2} / \mathrm{Hz}\right]$ at $1 \mathrm{~m}$, assumed to occur at $150 \mathrm{~m}$ depth with bubble flow rate $4 \mathrm{~L} / \mathrm{min}$. The curve indicates the spectrum estimated from the theoretical model based on Eq.9. [15], with a peak value $91 \mathrm{~dB}$ re $1 \mu \mathrm{Pa}^{2} / \mathrm{Hz}$ at $1 \mathrm{~m}(\sim 8 \mathrm{kHz})$ as marked.

The curve, shown in Figure 5, indicates the spectrum estimated from the theoretical model based on Eq. 19], considering ambient environment, including salinity, temperature, and the depth. Note that the curve may change depending on the changes of bubble sound time series and spectral methods. The maximum value of the bubble spectrum $\mathrm{SL}_{\mathrm{b}}=91 \mathrm{~dB}$ re $1 \mu \mathrm{Pa}^{2} / \mathrm{Hz}$ is found at the frequency of around $8 \mathrm{kHz}$. Simulations demonstrated that $90 \%$ of the energy in the bubble spectrum lies between 5.3 and $14.8 \mathrm{kHz}$. The propagation loss of the bubble sound at $8 \mathrm{kHz}$ is shown in Figure6(a).

\subsection{Ambient noise}

In the ocean, the frequency band of bubble radiation sound is particularly affected by ambient noise produced from the sea surface 19, 20, ship transit noise and traffic noise [27, 28, 21, 22, 23. Here we investigate the interaction of the three

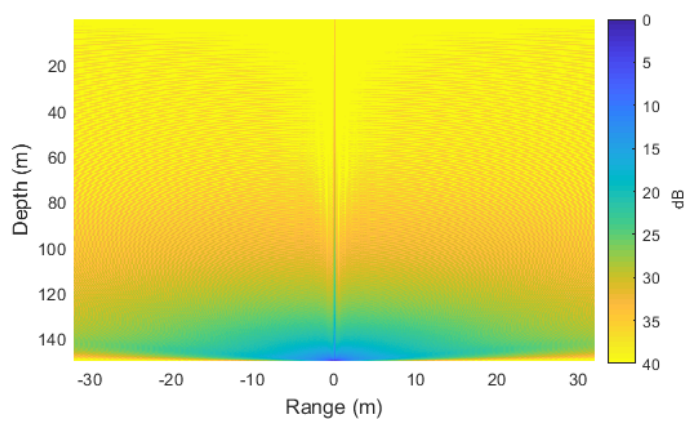

(a) bubble sound

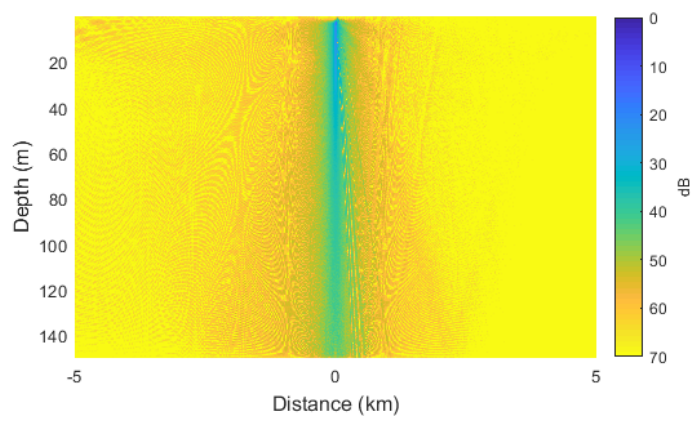

(b) ship noise

Figure 6: Propagation loss (PL) $[\mathrm{dB}]$ of different sound sources in the channel at $8 \mathrm{kHz}$, calculated from the Bellhop program [48. The $\mathrm{PL}_{\mathrm{b}}$ of bubble sound and the $\mathrm{PL}_{2}$ of ship noise changes significantly as the hydrophone range/distance increases, compared to the $\mathrm{PL}_{1}$ of surface noise as the hydrophone depth increases. The sound intensity reduces as the propagation loss increases. (a) Bubble sound $\mathrm{PL}_{\mathrm{b}}$. (b) Ship noise $\mathrm{PL}_{2}$.

types of noise sources and how they may affect the acoustic measurements.

\subsubsection{Sea surface noise}

The sea surface noise source level $\mathrm{SL}_{1}$ is computed from Eq.114. To specify the noise spectral level $\mathrm{NSL}_{1}$ shape, we consider a case of a relatively calm sea surface with wind speed at 1 knots, corresponding to the Sea State 1. The sea surface noise spectra, shown in Figure 7(a), is obtained by filtering the generated Gaussian noise with the designed FIR filter by considering the position of an acoustic receive hydrophone, $1 \mathrm{~m}$ off the seabed here. Note that the propagation loss of sea surface noise is relatively small in such shallow water, while the ship transit noise and traffic noise may experience much high propagation loss in the acoustic channel.

\subsubsection{Ship transit noise}

The ship transit noise is computed based on the RRS James Cook travelling at 14 knots in the central North Sea. Table 2 shows relevant parameters for the RRS James Cook. The channel prop- 


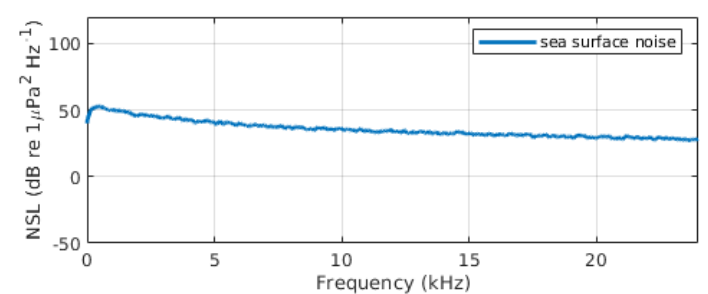

(a) sea surface noise

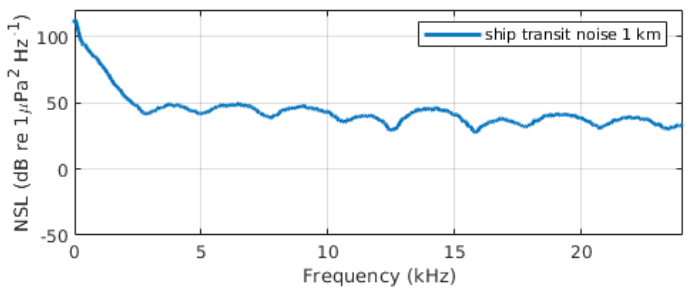

(c) ship transit noise, $1 \mathrm{~km}$

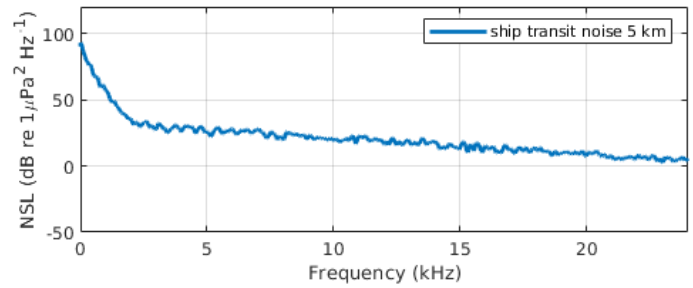

(e) ship transit noise, $5 \mathrm{~km}$

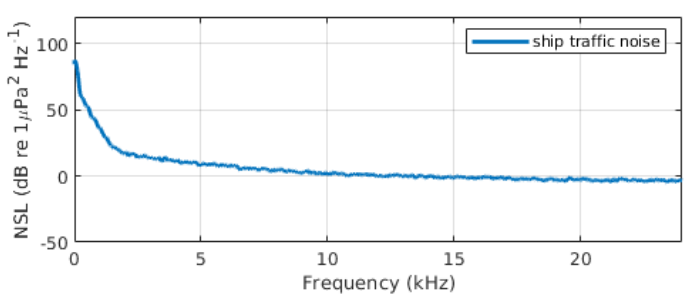

(b) ship traffic noise

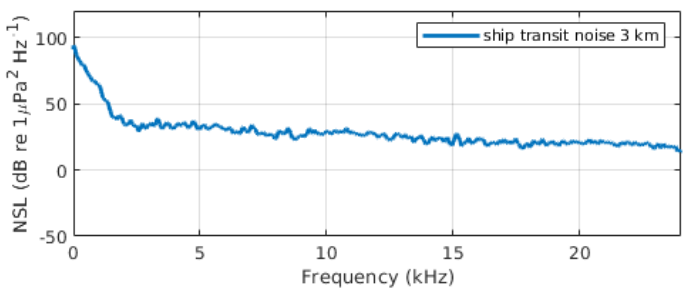

(d) ship transit noise, $3 \mathrm{~km}$

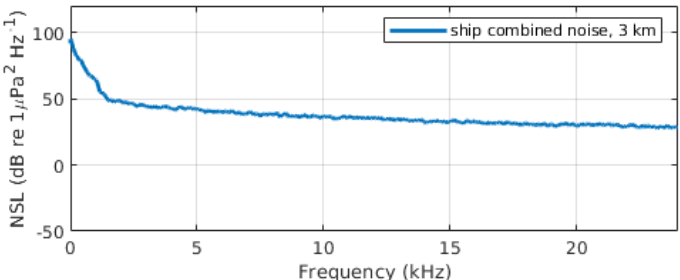

(f) combined noise, $3 \mathrm{~km}$

Figure 7: Noise spectral levels (NSL) of sea surface noise at depth of $149 \mathrm{~m}$ and ship noise at distances of 1-5 km. The ship noise dominates the ambient noise at distances of $1 \mathrm{~km}$, whereas the sea surface noise dominates the ambient noise at ship distances of $5 \mathrm{~km}$. (a) Sea surface noise, $149 \mathrm{~m}$ depth. (b) Ship traffic noise. (c) Ship transit noise, $1 \mathrm{~km}$. (d) Ship transit noise, $3 \mathrm{~km}$. (e) Ship transit noise, $5 \mathrm{~km}$. (f) Combined noise, surface+traffic + transit $(3 \mathrm{~km})$.

Table 2: Some characteristics of the ship 'James Cook'.

\begin{tabular}{ll}
\hline \hline Displacement & $5800 \mathrm{t}$ \\
Maximum speed & $16.00 \mathrm{knots}$ \\
Main propellers & $2 \times$ five-bladed inward turning \\
Propeller diameter & $3.6 \mathrm{~m}$ \\
& Diesel electric \\
Propulsion plant & $2 \times 2500 \mathrm{~kW}$ Teco dc mot \\
& $($ speed $0-180 \mathrm{rpm})$ \\
& $4 \times 1770 \mathrm{~kW}$ Wartsila $9 \mathrm{~L} 20$ \\
Power plant & $(1000 \mathrm{rpm}$ generators, $9 \mathrm{cylinders})$ \\
& $3 \times$ Siemens alternators, $60 \mathrm{~Hz}$ \\
\hline
\end{tabular}

agation loss of the ship radiated noise at $8 \mathrm{kHz}$ is shown in Figure 6(b).

The ship transit noise spectra at distances 1$5 \mathrm{~km}$, are shown in Figures 7 (c)-(e). It is seen that increasing the ship/hydrophone distance from $1 \mathrm{~km}$ to $3 \mathrm{~km}$, the magnitude of the ship noise spectral level $\mathrm{NSL}_{2}$ decreases by approximately 10$20 \mathrm{~dB}$ at $8 \mathrm{kHz}$. By comparing the noise spectral level (NSL) contribution of the sea surface agitation noise in Figure 7(a) and the ship noise in Fig- ures 7(c)-(e), we can see that the ship transit noise dominates the ambient noise field at distances less than $3 \mathrm{~km}$, whereas the sea surface noise dominates at distances above $3 \mathrm{~km}$. While ship transit noise is from specific ships nearby, the ship traffic noise is from all ship related noise sources in the vast ocean.

\subsubsection{Ship traffic noise}

The ship traffic noise is computed based on the distribution and types of distant vessels. Here we consider the noise sources with approximately equal engine powers and the vessels are considered equally distributed in the surrounding area. All vessels are assumed to have the same noise characteristics as the RRS James Cook travelling at 14 knots. According to the real-time ship tracker [68], the minimum and maximum distances to the hydrophone are assumed to be $\widehat{D}_{\text {min }}=5 \mathrm{~km}$ and $\widehat{\mathrm{D}}_{\max }=100 \mathrm{~km}$ (distance to the nearest shore), and the number of vessels is estimated as 300 (average number of vessels within $100 \mathrm{~km}$ in the North Sea). The ship traffic noise experiences considerable propagation losses at such long distances, reducing the masking potential of the distant ship 
noise to the bubble sound at the hydrophone.

The ship traffic noise spectra level is shown in Figure 7(b), agrees well with ship traffic noise measured and described in literature [27, 61]. By comparing the noise spectral level (NSL) contribution of the sea surface agitation noise in Figure 7(a) and the ship noise in Figures 7(c)-(e), we can see that ship traffic noise dominates the ambient noise at low frequencies, as a rescue of significant attenuation of high frequency signals at long distances.

\subsection{Impact assessment for gas flux measurement}

The impacts of the ambient noise, combined by sea surface noise and ship noise, on gas flux measurement are assessed to calculate the SNR at the hydrophone as a function of frequency. These estimations are based on running the designed model simulation 1000 times and under the assumption that the hydrophone placed at the same location 75 as it would experience the same bubble sound and ambient noise levels at each time. Masking effects are here estimated from modelled ambient noise spectral levels and quantified as ship distance increases to fulfill the same detection threshold $(6 \mathrm{~dB})$.

Figure 8 shows the smoothed SNR curves at different gas flow rates from $0.5 \mathrm{~L} / \mathrm{min}$ to $18.0 \mathrm{~L} / \mathrm{min}$. In each case, different hydrophone/bubble ranges (0.5-12 m) determines the minimum ship/hydrophone distance required so that reliable estimates of gas flux can be made (the detection threshold shown as the black dashed line). In all these cases, the SNR is substantially elevated as the ship/hydrophone distance increases less than $2.5 \mathrm{~km}$. However, when the ship/hydrophone distance is increased to beyond $2.5 \mathrm{~km}$, the SNR is nearly constant. This suggests that, the ship transit noise dominates as the vessel travels from $0 \mathrm{~km}$ to $2.5 \mathrm{~km}$, while the sea surface noise and ship traffic noise dominate beyond this value. This also corresponds to the comparable noise levels shown in Figures 7 (a) and (d).

At the gas flow rate $0.5 \mathrm{~L} / \mathrm{min}$ shown in Figure 8(a), the hydrophone is hardly to detect the weak bubble sound under such background noise no matter how far away the vessel is. When the gas flow rate is increased to $1.0 \mathrm{~L} / \mathrm{min}$ (Figure $8(\mathrm{~b})$ ), the hydrophone is able to detect the bubble sound at $0.5 \mathrm{~m}$ when the ship is on average $3740 \mathrm{~m}$ away. When the bubble flow rate is $4.0 \mathrm{~L} / \mathrm{min}$ (Figure $8(\mathrm{~d})$ ) and the hydrophone/bubble range is $2 \mathrm{~m}$, the focal vessel only contaminates the measurements at distances less than $2.5 \mathrm{~km}$. If the hydrophone is just able to detect the bubbles at a range of $6 \mathrm{~m}$, and the ship distance is shortened by $0.5 \mathrm{~km}$ (increase of ship noise level), the hydrophone can compensate the SNR loss by moving $2 \mathrm{~m}$ towards the gas seep centre to improve the bubble signal spectral level. In the case of gas flow rate $18.0 \mathrm{~L} / \mathrm{min}$ (Figure $8(\mathrm{f}))$, due to the loud bubble sound, the vessel can be close to the hydrophone.

The minimum ship/hydrophone distance, corresponding to an SNR equal to the detection threshold, can be determined from each of the Figures $8(\mathrm{~b})$ (f). Take Figure 8(d) as an example, the minimum ship/hydrophone distance is close to $2.3 \mathrm{~km}$ when the hydrophone/bubble range is $0.5 \mathrm{~m}$, while it has to be around $4.5 \mathrm{~km}$ when the hydrophone/bubble range is $6 \mathrm{~m}$. This is limited by the hydrophone detection threshold $(6 \mathrm{~dB})$. If the hydrophone/bubble range is increased, the ship/hydrophone distances should also be increased, to keep the SNR higher than the detection threshold.

\section{Experimental and statistical justification}

To verify the effectiveness and robustness of the presented noise assessment model, we conducted field work in the central North Sea to measure the seafloor noise, and analyze the statistical outliers of the simulation results.

\subsection{Comparison of noise measurement and model}

The noise measurement experiment was conducted in the central North Sea (coordinate $58^{\circ} 38^{\prime} 73^{\prime \prime} \mathrm{N}$, $\left.01^{\circ} 08^{\prime} 24^{\prime \prime} \mathrm{E}\right)$ using the RRS James Cook in September 2017 .

In the field work, an acoustic recorder with an absolutely calibrated hydrophone was attached on a lander mounted on the seafloor at depth $150 \mathrm{~m}$. The hydrophone was $1 \mathrm{~m}$ above the seafloor. The measured noise data is compared with the modelled noise, in which case the wind speed over the sea surface was around 11 knots (Sea State 4), the ship speed was 14 knots, and the ship/hydrophone distance was around $5 \mathrm{~km}$. The comparison result is shown in Figure 9 using $1 / 3$ octave bands.

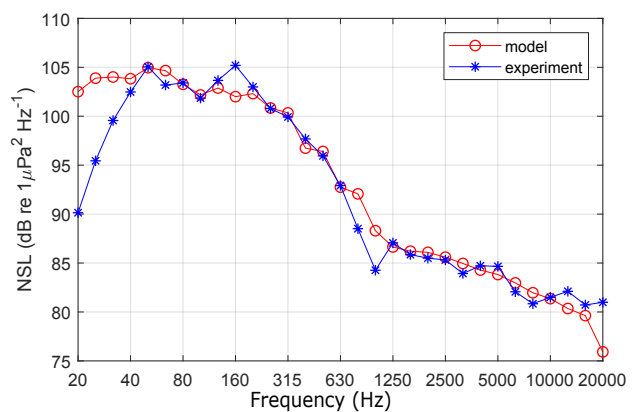

Figure 9: Comparison of the modelled received noise level using the proposed/selected noise model (source level models + Bellhop propagation model) and measured noise level. The ship speed is 14 knots, and the wind speed is 11 knots. 


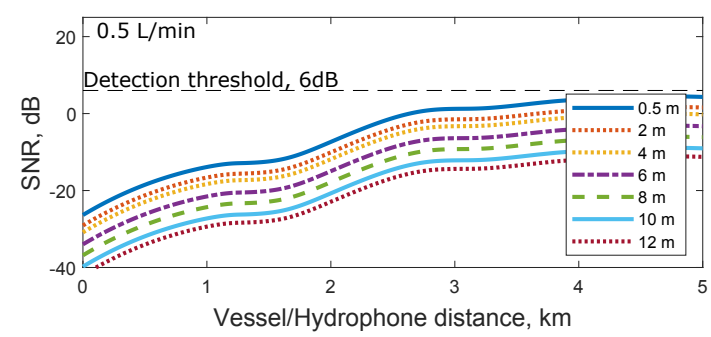

(a) $0.5 \mathrm{~L} / \mathrm{min}$

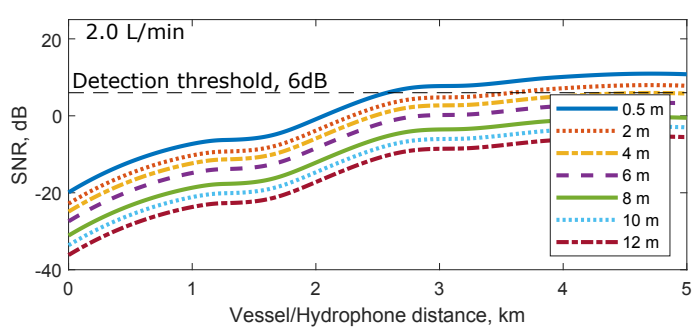

(c) $2.0 \mathrm{~L} / \mathrm{min}$

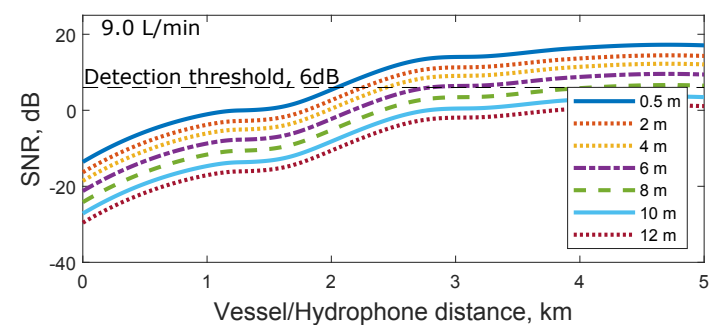

(e) $9.0 \mathrm{~L} / \mathrm{min}$

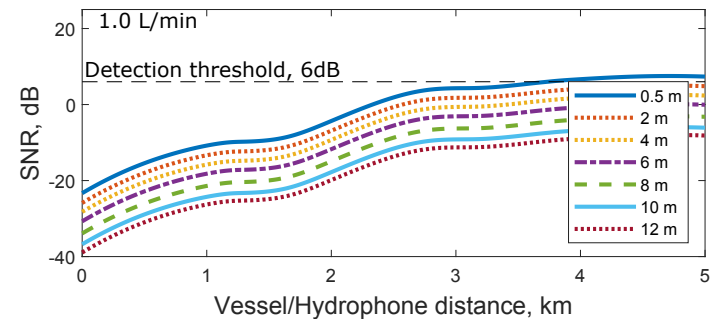

(b) $1.0 \mathrm{~L} / \mathrm{min}$

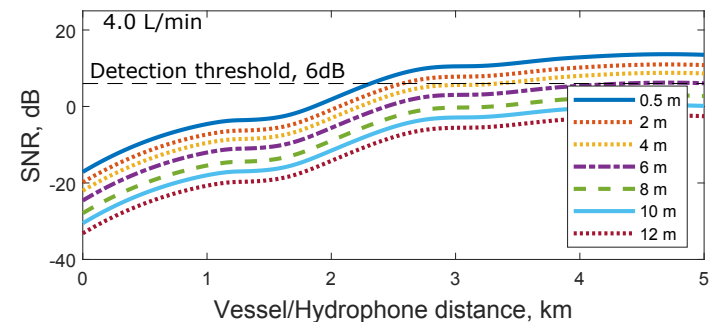

(d) $4.0 \mathrm{~L} / \mathrm{min}$

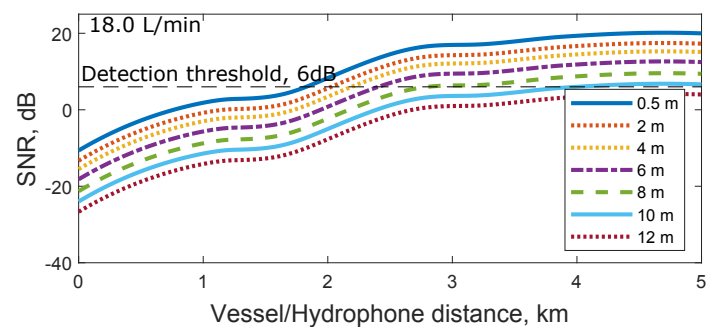

(f) $18.0 \mathrm{~L} / \mathrm{min}$

Figure 8: Smoothed signal to noise ratio (SNR) at various bubble volume rates from $0.5 \mathrm{~L} / \mathrm{min}$ to $18.0 \mathrm{~L} / \mathrm{min}$. Various ranges from the hydrophone to the gas flux centre are from $0.5 \mathrm{~m}$ to $12 \mathrm{~m}$, indicated as different color lines. The horizontal dashed line denotes the SNR detection threshold $=6 \mathrm{~dB}$. When the colored SNR lines are above the detection threshold, the recording system (hydrophone) is considered to be able to detect the bubble sound radiated from the seabed gas emissions, vice versa. (a) $0.5 \mathrm{~L} / \mathrm{min}$, maximum hydrophone range $<0.5 \mathrm{~m}$. (b) $1.0 \mathrm{~L} / \mathrm{min}$, maximum hydrophone range $<2 \mathrm{~m}$. (c) $2.0 \mathrm{~L} / \mathrm{min}$, maximum hydrophone range $<4 \mathrm{~m}$. (d) $4.0 \mathrm{~L} / \mathrm{min}$, maximum hydrophone range $<8 \mathrm{~m}$. (e) $9.0 \mathrm{~L} / \mathrm{min}$, maximum hydrophone range $<10 \mathrm{~m}$. (f) $18.0 \mathrm{~L} / \mathrm{min}$, maximum hydrophone range $<12 \mathrm{~m}$.

Generally, there is good agreement between the modelled and observed noise levels, with a maximum noise at $40-80 \mathrm{~Hz}$, typical of radiated noise from ships. Above these frequencies the level decreases by about $6 \mathrm{~dB}$ per octave until the surface agitation noise dominates at high frequencies. There is a band of strong tones measured at approximately $160 \mathrm{~Hz}$ caused by the tonal harmonics of the blade rates, which are, not shown in the model. Then at other frequency bands, the modelled level yields agreement within $\pm 5 \mathrm{~dB}$ compared to the measured data. Errors arise from simplifications in the models, and assumptions made when calculating propagation loss due to timevarying sound speed in the water column, unknown seabed bathymetry, and complex properties of the seabed. Our current experience indicates that the total error is a few $\mathrm{dB}$, which is small, but it has to be accepted that the good or bad wake field, pro- peller design, and the non-stationary of the ship can also cause anomaly and no quantification of this has yet been made.

\subsection{Statistical analysis}

As the ambient noise and the bubble emission sound is non-stationarity, it is necessary to show the statistical outliers. In the 1000-time Monte Carlo simulations, the gas flow rate is set to $1.0 \mathrm{~L} / \mathrm{min}$, and the detection threshold is set to $6 \mathrm{~dB}$. The simulation results are shown in Figure 10. The PDF, smoothed using the kernel estimator, suggests that the distance threshold is distributed between $3400 \mathrm{~m}$ and $4100 \mathrm{~m}$, centering at around $3740 \mathrm{~m}$. Then, we use the kernel smoothing function to draw the receiver operating characteristic (ROC) curve, which shows the PFA. At the average distance threshold $3740 \mathrm{~m}$, the PFA is about $50 \%$. To be close to certain that underwater gas 
flux determination is successful, then the minimum ship/hydrophone distance should be $4100 \mathrm{~m}$.

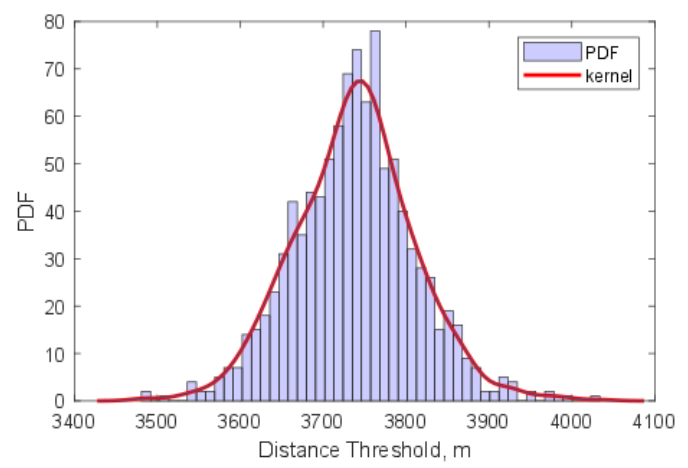

(a) Probability density function (PDF)

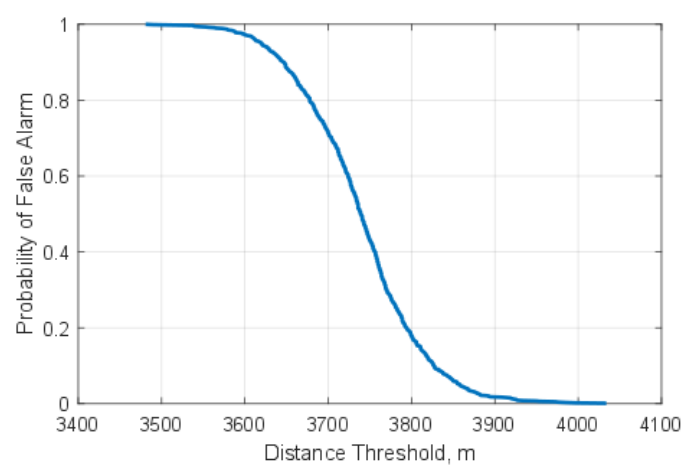

(b) Receiver operating characteristic (ROC) curve

Figure 10: Statistical outliers due to non-stationarity of the noise and bubble sound. (a) probability density function (PDF) of distance threshold with 1000 times Monte Carlo simulation. (b) Receiver operating characteristic (ROC) curve showing the probability of false alarm.

\section{Conclusions and discussions}

This study described an attempt to predict the dominant noise source, maximum bubble/hydrophon range, and minimum ship/hydrophone distance using a numerical model, for ensuring valid gas leakage detection and quantification from sub-seabed gas flux measurement in the field. The modelling results (Figure 8 showed that the prediction is possible and can be applicable in a range of the marine acoustic environments. The modelling of underwater acoustic signatures are complicated in different marine environments. We have shown that the signal-to-noise ratio at an underwater acoustic recording system has been clearly modelled incorporating noise sources (sea surface agitation and shipping), bubble sound, and the acoustic propagation channel. The most important contribution of the modelling with its results is that it provides a statistical reference to avoid blind positioning of ship which radiates noise during underwater acoustic works, such that the measurement can be successfully conducted in the acoustic environment with high-enough signal-to-noise ratio.

\subsection{Variation of acoustic signatures}

In the oceans, the acoustic signature can be affected by a variety of factors. Here we considered a relatively calm sea surface with wind speed $v_{\mathrm{w}}=$ 1 knots corresponding to Sea State 1. However, if the wind speed is higher than this level, reaching Sea State 4 or 5 , it may produce significant breaking waves and can be the dominant noise source in a large area. The ship traffic noise can also be the dominant source when ship traffic is heavy.

The other important factor that cannot be ignored is the vessel specifications, such as size, speed, propulsion type, and load [76, 77]. Besides the vessel characteristics, the acoustic signature at a given distance may also be influenced by interference patterns due to multiple radiation points from the ship, non-stationary of the ship, and multipath propagation such as the Lloyds' mirror effect (LME) (Bellhop has covered this). Interference patterns vary according to the depth and distance of source and hydrophone, bathymetry, sediment composition, the SSP, and the fact that the ship at close distance can no longer be considered as a point source 78. The assessment results show pronounced variation in the simulations from actual source levels. Therefore, because of the complex propagation patterns, the noise levels around a nearby vessel, particularly in shallow water, are very difficult to predict 78 .

Furthermore, we paid attention only to noise radiated from a single vessel traveling close to the field site. However, once a number of ship transit noise sources, or self-generated noise from remotely operated underwater vehicle (ROV) or autonomous underwater vehicle (AUV) positioning a hydrophone near origin of the gas flux, the Gaussian noise model may not be valid to model the ship noise and the specific source statistics and geometries should be considered. Modelling of ship noise impacts, based on noise source levels and propagation models, depends heavily on the chosen vessel characteristics and environmental factors and should not solely be depended upon in noise impact assessments, but should be grounded in and verified by actual measurements 78 . In addition, in practice, to minimize noise interference, at least for the research vessels, all engines, generators, and echo sounders should be switched off or minimized during the gas flux measurements.

\subsection{Outlooks for future work}

As Leighton and White 15 pointed out, until a good model for the bubble source level has 
been validated, particularly at depth, there remains uncertainty in the signal level and papers such as this can only address the noise component of the SNR. The presented noise impact assessment model can be used as a prediction bench mark and offer chance to investigate background noise in model scale at much lower cost and ultimately to reduce the probability of failure of the marine acoustic works, not only for the measurements of seabed gas fluxes, but also for wider underwater applications. Much more research in the related mechanisms is needed together with field measurement of the SNR such as on the seafloor of the central North Sea.

\section{Acknowledgments}

Funding for this work was provided by NERC grant NE/N01610/1 and the European Unions Horizon 2020 research and innovation programme under the grant agreement number 654462 (STEMMCCS). We are grateful to Dr. Anna Lichtschlag for providing the sound speed profile collected at the Goldeneye Complex in the North Sea, as well as the Captain of the RRS James Cook and crew for enabling the scientific measurements at sea during JC152.

\section{References}

[1] J. Calleya, R. Pawling, A. Greig, Ship impact model for technical assessment and selection of Carbon dioxide Reducing Technologies (CRTs), Ocean Engineering 97 (2015) 82-89. doi:10.1016/j.oceaneng.2014.12. 014

[2] D. Raynaud, J. Barnola, J. Chappellaz, T. Blunier, A. Indermühle, B. Stauffer, The ice record of greenhouse gases: a view in the context of future changes, Quaternary Science Reviews 19 (1) (2000) 9-17. doi : 10.1016/S0277-3791(99) 00082-7

[3] J. G. Titus, R. A. Park, S. P. Leatherman, J. R. Weggel, M. S. Greene, P. W. Mausel, S. Brown, C. Gaunt, M. Trehan, G. Yohe, Greenhouse effect and sea level rise: the cost of holding back the sea, Coastal Management 19 (2) (1991) 171-204. doi: 10.1080/08920759109362138

[4] M. Schmidt, P. Linke, S. Sommer, D. Esser, S. Cherednichenko, Natural $\mathrm{CO}_{2}$ seeps offshore Panarea: A test site for subsea $\mathrm{CO}_{2}$ leak detection technology, Marine Technology Society Journal 49 (1) (2015) 19-30. doi:10.4031/MTSJ.49.1.3

[5] H. Wang, P. Zhou, Z. Wang, Experimental and numerical analysis on impacts of significant factors on carbon dioxide absorption efficiency in the carbon solidification process, Ocean Engineering 113 (2016) 133-143. doi:10.1016/j.oceaneng.2014.12.014

[6] P. Zhou, H. Wang, Carbon capture and storageSolidification and storage of carbon dioxide captured on ships, Ocean Engineering 91 (2014) 172-180. doi: 10.1016/j.oceaneng. 2014.09.006

[7] B. Windén, M. Chen, N. Okamoto, D. K. Kim, E. McCaig, A. Shenoi, P. Wilson, Investigation of offshore thermal power plant with carbon capture as an alternative to carbon dioxide transport, Ocean Engineering
76 (2014) 152-162. doi:10.1016/j.oceaneng.2013. 07.016

[8] J. Blackford, H. Stahl, J. M. Bull, B. J. Berges, M. Cevatoglu, A. Lichtschlag, D. Connelly, R. H. James, J. Kita, D. Long, et al., Detection and impacts of leakage from sub-seafloor deep geological carbon dioxide storage, Nature Climate Change 4 (11) (2014) 1011. doi:10.1038/nclimate2381

[9] H. K. Hvidevold, G. Alendal, T. Johannessen, A. Ali, Survey strategies to quantify and optimize detecting probability of a $\mathrm{CO}_{2}$ seep in a varying marine environment, Environmental Modelling \& Software 83 (2016) 303-309. doi:10.1016/j.envsoft.2016.06.006

[10] B. J. Bergès, T. G. Leighton, P. R. White, Passive acoustic quantification of gas fluxes during controlled gas release experiments, International Journal of Greenhouse Gas Control 38 (2015) 64-79. doi: 10.1016/j.ijggc.2015.02.008

[11] D. Atamanchuk, A. Tengberg, D. Aleynik, P. Fietzek, K. Shitashima, A. Lichtschlag, P. O. Hall, H. Stahl, Detection of $\mathrm{CO}_{2}$ leakage from a simulated sub-seabed storage site using three different types of $\mathrm{pCO}_{2}$ sensors, International Journal of Greenhouse Gas Control 38 (2015) 121-134. doi:10.1016/j.ijggc.2014. 10.021

[12] P. Taylor, H. Stahl, M. E. Vardy, J. M. Bull, M. Akhurst, C. Hauton, R. H. James, A. Lichtschlag, D. Long, D. Aleynik, et al., A novel sub-seabed $\mathrm{CO}_{2}$ release experiment informing monitoring and impact assessment for geological carbon storage, International Journal of Greenhouse Gas Control 38 (2015) 3-17. doi:10.1016/j.ijggc.2014.09.007

[13] J. M. Pearce, M. C. Akhurst, D. J. Jones, C. J. Vincent, J. H. Booth, Pathways from pilot to demonstration: how can research advance $\mathrm{CO}_{2}$ geological storage deployment?, British Geological Survey, http://nora.nerc.ac.uk/id/eprint/514069/1/OR16029.pdf, 2016.

[14] M. A. Ainslie, Principles of sonar performance modelling, Springer, $2010 . \quad$ doi: 10.1007/978-3-540-87662-5

[15] T. G. Leighton, P. R. White, Quantification of undersea gas leaks from carbon capture and storage facilities, from pipelines and from methane seeps, by their acoustic emissions 468 (2138) (2012) 485-510. doi:10.1098/rspa.2011.0221

[16] L. Pizzuti, C. dos Santos Guimarães, E. G. Iocca, P. H. S. de Carvalho, C. A. Martins, Continuous analysis of the acoustic marine noise: A graphic language approach, Ocean Engineering 49 (2012) 56-65. doi:10.1016/j.oceaneng.2012.04.004

[17] D. Wittekind, M. Schuster, Propeller cavitation noise and background noise in the sea, Ocean Engineering 120 (2016) 116-121. doi:10.1016/j.oceaneng.2015. 12.060

[18] R. P. Hodges, Underwater acoustics: Analysis, design and performance of sonar, John Wiley \& Sons, 2011. doi:10.1002/9780470665244.

[19] P. Asolkar, A. Das, S. Gajre, Y. Joshi, Comprehensive correlation of ocean ambient noise with sea surface parameters, Ocean Engineering 138 (2017) 170-178. doi:10.1016/j.oceaneng.2017.04.033

[20] J. Liu, I. Lin, C. Chu, Effects of sediment properties on surface-generated ambient noise in a shallow ocean, Ocean engineering 32 (16) (2005) 1887-1905. doi: 10.1016/j.oceaneng.2005.04.001

[21] D.-Q. Li, J. Hallander, T. Johansson, Predicting underwater radiated noise of a full scale ship with model testing and numerical methods, Ocean Engineering 161 (2018) 121-135. doi:10.1016/j.oceaneng.2018. 03.027 
[22] A. Brooker, V. Humphrey, Measurement of radiated underwater noise from a small research vessel in shallow water, Ocean Engineering 120 (2016) 182-189. doi:10.1016/j.oceaneng.2015.09.048

[23] P. Kellett, O. Turan, A. Incecik, A study of numerical ship underwater noise prediction, Ocean Engineering 66 (2013) 113-120. doi:10.1016/j.oceaneng.2013. 04.006

[24] T. G. Leighton, D. G. Coles, M. Srokosz, P. R. White, D. K. Woolf, Asymmetric transfer of $\mathrm{CO}_{2}$ across a broken sea surface, Scientific reports 8 (1) (2018) 8301. doi:10.5258/SOTON/D0492

[25] I. M. Brooks, M. J. Yelland, R. C. Upstill-Goddard P. D. Nightingale, S. Archer, E. d'Asaro, R. Beale, C. Beatty, B. Blomquist, A. A. Bloom, et al., Physical exchanges at the air-sea interface: Uk-solas field measurements, Bulletin of the American Meteorological Society 90 (5) (2009) 629-644. doi:10.1175/ 2008BAMS2578.1.

[26] I. Leifer, D. Culling, Formation of seep bubble plumes in the coal oil point seep field, Geo-Marine Letters 30 (3-4) (2010) 339-353. doi:10.1007/ s00367-010-0187-x

[27] G. M. Wenz, Acoustic ambient noise in the ocean: Spectra and sources, J. Acoust. Soc. Am. 34 (12) (1962) 1936-1956. doi:10.1121/1.1909155

[28] F. C. Rodney, Underwater acoustic systems (1990). doi:10.1007/978-1-349-20508-0

[29] F. B. Jensen, W. A. Kuperman, M. B. Porter H. Schmidt, Computational ocean acoustics, Springer Science \& Business Media, 2000. doi:10.1007/ 978-1-4419-8678-8

[30] J. Li, Y. V. Zakharov, Efficient use of space-time clustering for underwater acoustic communications, IEEE Journal of Oceanic Engineering 43 (1) (2018) 173-183. doi:10.1109/JOE. 2017.2688558

[31] J. Li, Y. V. Zakharov, B. Henson, Multibranch autocorrelation method for Doppler estimation in underwater acoustic channels, IEEE Journal of Oceanic Engineering 99 (4) (2017) 1099-1113. doi:10.1109/JOE. 2017.2761478

[32] J. Li, L. Liao, Y. V. Zakharov, Space-time cluster combining for UWA communications, in: OCEANS 2016-Shanghai, IEEE, 2016, pp. 1-6. doi:10.1109/ OCEANSAP. 2016.7485344.

[33] A. D. Phelps, T. G. Leighton, Oceanic bubble population measurements using a buoy-deployed combination frequency technique, IEEE Journal of Oceanic Engineering 23 (4) (1998) 400-410. doi:10.1109/48. 725234

[34] G. E. Updegraff, V. C. Anderson, Bubble noise and wavelet spills recorded $1 \mathrm{~m}$ below the ocean surface, J. Acoust. Soc. Am. 89 (5) (1991) 2264-2279. doi: 10.1121/1.400917

[35] X. Lurton, An Introduction to Underwater Acoustics: Principles and Applications, Springer-Praxis, 2010. doi:10.3397/1.3525563

[36] L. Kang, Q. Meng, Q. Liu, Fundamental diagram of ship traffic in the Singapore Strait, Ocean Engineering 147 (2018) 340-354. doi:10.1016/j.oceaneng. 2017. 10.051

[37] R. L. Dawe, Detection threshold modelling explained, Tech. Rep. 1 (1997).

[38] F. Dunn, W. Hartmann, D. Campbell, N. H. Fletcher, Springer handbook of acoustics, Springer, 2015. doi: 10.1007/978-1-4939-0755-7

[39] A. Vazquez, R. Manasseh, R. Sánchez, G. Metcalfe, Experimental comparison between acoustic and pressure signals from a bubbling flow, Chemical Engineering Science 63 (24) (2008) 5860-5869. doi:10.1016/ j.ces.2008.08.032
[40] R. Manasseh, R. LaFontaine, J. Davy, I. Shepherd, Y.-G. Zhu, Passive acoustic bubble sizing in sparged systems, Experiments in Fluids 30 (6) (2001) 672-682. doi:10.1007/s003480000245.

[41] K. Thomanek, O. Zielinski, H. Sahling, G. Bohrmann, Automated gas bubble imaging at sea floor-a new method of in situ gas flux quantification, Ocean Science 6 (2) (2010) 549-562. doi:10.5194/ os-6-549-2010

[42] P. Linke, M. Haeckel, J. Schneider von Deimling, L. Vielstädte, M. Schmidt, J. Karstens, C. Berndt, H. Herreilers, A. Lichtschlag, R. James, et al., Fluxes of $\mathrm{CO}_{2}$ from natural seep sites and Sleipner storage site no. 265847, $\mathrm{ECO}_{2}$ Project Office, 2014.

URL https://www.lombardiresearchgroup.com/ files/fluxes_of_co2_from_natural_seep_sites_ and_sleipner_storage_site-05082015-143518.pdf

[43] M. Veloso, J. Greinert, J. Mienert, M. D. Batist, A new methodology for quantifying bubble flow rates in deep water using splitbeam echosounders: Examples from the Arctic offshore NW-Svalbard, Limnology and Oceanography: Methods 13 (6) (2015) 267-287. doi: 10.1002/lom3.10024

[44] I. Leifer, I. MacDonald, Dynamics of the gas flux from shallow gas hydrate deposits: interaction between oily hydrate bubbles and the oceanic environment, Earth and Planetary Science Letters 210 (3) (2003) 411-424. doi:10.1016/S0012-821X(03)00173-0

[45] M. Torres, J. McManus, D. Hammond, M. D. Angelis, K. Heeschen, S. Colbert, M. Tryon, K. Brown, E. Suess, Fluid and chemical fluxes in and out of sediments hosting methane hydrate deposits on Hydrate Ridge, OR, I: Hydrological provinces, Earth and Planetary Science Letters 201 (3) (2002) 525-540. doi:10.1016/S0012-821X(02)00733-1

[46] E. J. Sauter, S. I. Muyakshin, J. L. Charlou, M. Schlüter, A. Boetius, K. Jerosch, E. Damm, J.-P. Foucher, M. Klages, Methane discharge from a deepsea submarine mud volcano into the upper water column by gas hydrate-coated methane bubbles, Earth and Planetary Science Letters 243 (3) (2006) 354-365. doi:10.1016/j.epsl.2006.01.041

[47] H. Sahling, G. Bohrmann, Y. G. Artemov, A. Bahr, M. Brüning, S. A. Klapp, I. Klaucke, E. Kozlova, A. Nikolovska, T. Pape, et al., Vodyanitskii mud volcano, sorokin trough, black sea: Geological characterization and quantification of gas bubble streams, Marine and Petroleum Geology 26 (9) (2009) 1799-1811. doi:10.1016/j.marpetgeo.2009.01.010

[48] M. B. Porter, The bellhop manual and users guide: Preliminary draft Heat, Light, and Sound Research, Inc., La Jolla, CA, USA, Tech. Rep. URL http://esme.bu.edu/data/papers/ HLS-2010-1.pdf

[49] R. J. Urick, Principles of Underwater Sound (4th edition), PENINSULA PUBLISHING, 2013.

[50] T. G. Leighton, The acoustic bubble, ISBN: 0-1244190- - doi:10.1017/S0022112094214519.

[51] P. Lage, R. Espósito, Experimental determination of bubble size distributions in bubble columns: prediction of mean bubble diameter and gas hold up, Powder technology 101 (2) (1999) 142-150. doi:10.1590/ S0104-66322004000100008

[52] F. Lehr, M. Millies, D. Mewes, Bubble-size distributions and flow fields in bubble columns, AIChE Journal 48 (11) (2002) 2426-2443. doi:10.1002/aic. 690481103

[53] G. J. Orris, M. Nicholas, Collective oscillations of fresh and salt water bubble plumes, J. Acoust. Soc. Am. 107 (2) (2000) 771-787. doi:10.1121/1.428253

[54] I. Leblond, C. Scalabrin, L. Berger, Acoustic monitor- 
ing of gas emissions from the seafloor. part i: quantifying the volumetric flow of bubbles, Marine Geophysical Research 35 (3) (2014) 191-210. doi:10.1007/ s11001-014-9223-y

[55] K. Yeh, K. Kwan, A comparison of numerical integrating algorithms by trapezoidal, lagrange, and spline approximation, Journal of Pharmacokinetics and Pharmacodynamics 6 (1) (1978) 79-98. doi:10.1007/ BF01066064.

[56] M. A. Ainslie, T. G. Leighton, Near resonant bubble acoustic cross-section corrections, including examples from oceanography, volcanology, and biomedical ultrasound, J. Acoust. Soc. Am. 126 (5) (2009) 2163-2175. doi:10.1121/1.3180130

[57] G. Siedler, H. Peters, Properties of sea water, Oceanography (1986) 233-264.

[58] R. Manasseh, A. Nikolovska, A. Ooi, S. Yoshida, Anisotropy in the sound field generated by a bubble chain, Journal of Sound and Vibration 278 (4-5) (2004) 807-823. doi:10.1016/j.jsv.2003.10.015

[59] H. Ochi, Y. Watanabe, T. Shimura, Measurement of absorption loss at $80 \mathrm{kHz}$ band for wideband underwater acoustic communication, Japanese Journal of Applied Physics 47 (5S) (2008) 4366. doi:10.1143/JJAP. 47.4366

[60] A. F. Harris III, M. Zorzi, Modeling the underwater acoustic channel in ns2, in: Proceedings of the 2nd international conference on Performance evaluation methodologies and tools, ICST (Institute for Computer Sciences, Social-Informatics and Telecommunications Engineering), 2007, p. 18. doi:10.1145/ 1345263.1345286

[61] B. J. Bauer, T. Howlett, Aerographer's Mate 1 \& C Navel Education and Training Professional Development and Technology Center, 1995.

URL https://www.weather.gov/media/zhu/ZHU_ Training_Page/Met_Tutorials/Met_Tutorial.pdf

[62] M. Buckingham, A theoretical model of ambient noise in a low-loss, shallow water channel, J. Acoust. Soc. Am. 67 (4) (1980) 1186-1192. doi:10.1121/1.384161.

[63] D. M. Chapman, An improved kirchhoff formula for reflection loss at a rough ocean surface at low grazing angles, J. Acoust. Soc. Am. 73 (2) (1983) 520-527. doi:10.1121/1.388997.

[64] C. Harrison, Ocean propagation models, Applied Acoustics 27 (3) (1989) 163-201. doi:10.1016/ 0003-682X (89) 90059-5

[65] M. Solan, C. Hauton, J. A. Godbold, C. L. Wood, T. G. Leighton, P. R. White, Anthropogenic sources of underwater sound can modify how sediment-dwelling invertebrates mediate ecosystem properties, Scientific reports 6 (2016) 20540. doi:10.1038/srep20540

[66] D. K. Wittekind, A simple model for the underwater noise source level of ships, Journal of Ship production and design 30 (1) (2014) 7-14. doi:10.5957/JSPD . 30. 1.120052

[67] E. Bartle, The choice of appropriate tools (technologies), procedures and strategies can make the difference between the success and failure of a research expedition. (2003).

URL http://www . mar-eco.no/learning-zone/ backgrounders/deepsea_research/mareco_ teechnology.html

[68] Marine Traffic. (2018).

URL https : //www . marinetraffic.com

[69] A. Chadwick, Review confirms Goldeneye storage capability and capacity, Tech. Rep. 1, British Geological Survey (2015).

URL https ://www . bgs . ac.uk/news/docs/Goldeneye_ C02_storage_Press_Release.pdf

[70] Shell, Goldeneye Gas Platform, United Kingdom.
(2017).

URL projects/goldeneye/

71] T. G. Leighton, G. Robb, Preliminary mapping of void fractions and sound speeds in gassy marine sediments from subbottom profiles, J. Acoust. Soc. Am. 124 (5) (2008) EL313-EL320. doi:10.1121/1.2993744

[72] A. Stevenson, B. Tait, A. Richardson, T. Smith, R. Nicolson, H. Stewart, The geochemistry of sea-bed sediments of the United Kingdom Continental Shelf: the North Sea, Hebrides and West Shetland shelves, and the Malin-Hebrides sea area, British Geological Survey, 1995.

[73] O. Paramor, K. Allen, M. Aanesen, C. Armstrong, T. J. Hegland, W. Le Quesne, G. Piet, J. Raakjær, S. Rogers, R. van Hal, et al., MEFEPO: Making the European Fisheries Ecosystem Plan Operational: North Sea Atlas, Tech. Rep. 1, University of Liverpool (2009).

[74] M. B. Porter, The KRAKEN normal mode program Tech. Rep. 1-198, Navel Research Lab Washington D.C. (1992).

URL http://www.dtic.mil/dtic/tr/fulltext/u2/ a252409.pdf

[75] J. Li, DOA tracking in time-varying underwater acoustic communication channels, in: MTS/IEEE OCEANS 2017-Aberdeen, no. 17303460, 2017, pp. 19. doi:10.1109/OCEANSE. 2017.8084563

[76] M. F. McKenna, D. Ross, S. M. Wiggins, J. A. Hildebrand, Underwater radiated noise from modern commercial ships, J. Acoust. Soc. Am. 131 (1) (2012) 92103. doi:10.1121/1.3664100

[77] M. F. McKenna, S. M. Wiggins, J. A. Hildebrand, Relationship between container ship underwater noise levels and ship design, operational and oceanographic conditions, Scientific reports 3 (2013) 1-49. doi:10. 1038/srep01760

[78] L. Hermannsen, K. Beedholm, J. Tougaard, P. T. Madsen, High frequency components of ship noise in shallow water with a discussion of implications for harbor porpoises (phocoena phocoena), J. Acoust. Soc. Am. 136 (4) (2014) 1640-1653. doi:10.1121/1. 4893908 